\title{
Research and Practice of Online and Offline Blended Teaching Mode
}

\author{
Xianzhen Ren*, Zhibin Zhang and Xiuhua Geng \\ Software and information department Beijing Information Technology College Beijing, China \\ *Corresponding author.Email: rxz90@126.com
}

\begin{abstract}
Online and offline blended teaching mode is an inevitable trend in the digital era. Flexible application of this teaching mode can improve students' learning interest and enthusiasm.Based on the new teaching model, this paper mainly discusses the practice of applying this model to specific courses, and analyzes its advantages and disadvantages, as well as the future research direction.
\end{abstract}

Keywords: Online, Offline, Blended teaching mode.

\section{INTRODUCTION}

With the rapid development of modern information technology, a large number of digital resources based on multimedia have emerged. Human beings are stepping into the digital transmission system based on highspeed.However, modern information technology can not automatically change the teaching effect. What really affects the teaching effect is the teaching mode chosen by teachers. The development of modern information technology provides unprecedented technical support for the reform of teaching mode.

Under the guidance of certain educational ideas, teaching theories and learning theories, the teaching mode is a stable structural form of teaching activities under certain circumstances, a set of methodology system for carrying out teaching activities, and a relatively stable framework and procedure of teaching activities based on certain teaching theories.

The teaching mode is the embodiment of teaching theory, and at the same time It is directly oriented to teaching practice and guides teaching practice, so it is operable.

The teaching mode provides people with a more specific framework of teaching behavior than the abstract theory. It clearly presents the teaching procedure and specifies the teaching behavior of teachers, so teachers have rules to follow in teaching works.

The teaching mode is the bridge between teaching theories and practices. It is the application of teaching theories and plays a direct guiding role in teaching practices. It is also a theoretical and concise summary of teaching practices, which can enrich and develop teaching theories. In short, the teaching mode is guided by certain theories, which needs to complete the established teaching objectives and contents, and show a certain sequence of teaching activities and its methods and strategies.

With the advent of the digital age, new requirements have been put forward for the education mode. John Dewey said that "if we still educate students in the way we did yesterday, we will deprive them of their future. The essence of education is to help students learn limited things in school, and let them have the ability to get more things in society. Therefore, education must keep pace with the pace of social development. It is necessary to fundamentally creates a new type of teaching mode based on digital education resources, which makes full use of existing digital tools, applies digital means and organically combines knowledge systems and teaching operations, focuses on the computer network technology and digital resources tools. In this new teaching mode, the rapid development of modern information technology is the tool of presentation, inquiry, interactive and design to realize the reform of teaching mode.

\section{RELATED WORK}

In the traditional face-to-face teaching mode, Course teaching is mainly based on teacher classroom lectures in class, and students can only use the remaining time in 
the classroom or spare time for operation practice. Traditional classroom teaching is usually carried out orderly under the guidance of teachers. Students' thinking is easy to be led by teachers, which leads to students' lack of opportunity to think. The disadvantage of this teaching model is that I teach you to learn, I tell you to listen. Therefore, it not only affects the improvement of students' learning quality, but also affects the development of students' potential ability.

In order to change the disadvantages of the traditional face-to-face teaching mode,We can effectively use Bitc(Beijing Information Technology College) online platform and use digital educational resources to organize teaching, which can dicover students' intellectual potential and stimulate their innovative thinking. Digital resources enter the classroom, breaking the traditional teaching model, eliminating the disadvantages of duck-filling teaching, and greatly improving students' comprehensive abilities.

This paper mainly discusses how to effectively use the digital teaching resources of Bitc online platform to construct a new teaching mode-online and offline blended teaching mode, as shown in Figure 1.This paper takes the data structure and algorithm analysis course as an example.Bitc online course teaching platform can support flexible construction of courses, guidance management before class, teaching management in class,learning management after class,and it also supports students' autonomous learning and other functions. Through the innovative application of online and offline blended teaching, students' comprehensive ability can be improved in an all-round way.

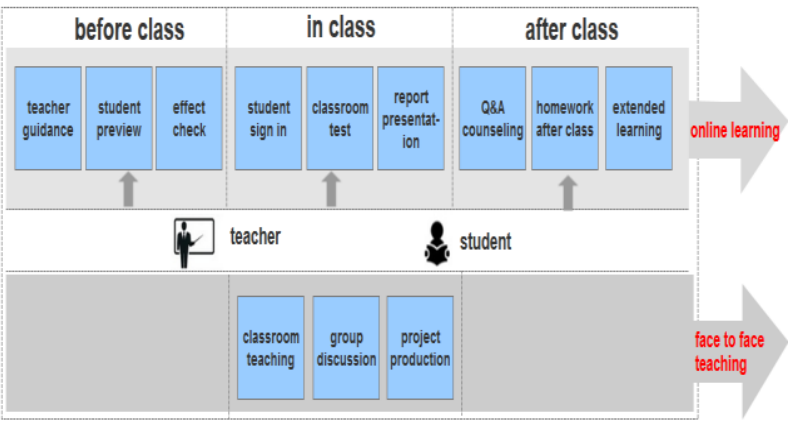

Figure 1 Online and offline blended teaching mode

\section{ONLINE AND OFFLINE BLENDED TEACHING MODE}

\subsection{Online Resources Design and Planning}

In the online and offline blended teaching mode, the online resources follow the professional top-level design, carry out the overall planning of the course, and the curriculum resources are designed on the premise of the composition of the professional teaching contents and curriculum system. Through the Bitc platform to build online courses, reasonably arrange and use teaching resources such as teaching videos, micro lessons, documents, PPT, animation, pictures, etc, organize students to carry out independent online learning, and assess students through chapter tests, homework after class, online tests, etc. On the other hand, in the classroom, teaching activities such as faceto-face explanation, practical operation and case analysis are arranged reasonably. Objective evaluation of students is carried out through multiple perspectives and process assessment mechanism. This online teaching method makes full use of the advantages of multimedia technology, and strives to realize the diversification of online teaching forms and materials.

Online teaching of this course is designed from three aspects: before, in and after class. Video, PPT and other learning materials will be released before class. Students can use these resources to preview before class. They can have a comprehensive grasp of the knowledge to be talked about, prepare relevant materials, make full preparation for class. This makes learning more purposeful. In class, students learn and operate according to the teaching video, and after each chapter is studied, a chapter quiz is conducted to give timely feedback on the learning effect. In order to ensure the learning effect and teaching quality, a quiz is arranged every 2 weeks and a phased examination is carried out every 4 weeks. After class, students complete and submit the homework assigned by teachers on time, and teachers will review and feedback in time. Teachers design discussion topics related to the course to extend the learned knowledge points. Students can express their own opinions according to the discussion topics. Teachers can view and reply to discussions. In this way, the interactive effect of teaching and learning is realized. Teachers regularly arranges Tutoring Q\&A to solve the difficult problems encountered by students in self-study, so as to strengthen the learning effect.The online course assessment method focuses on assessing the completion of students' online courses, with a full range of assessments in conjunction with chapter quizzes, assignments, and test scores.

\subsection{Requirements for Offline Learning}

The offline study of the course is mainly for students to obtain basic knowledge through online learning before class, and apply the learned knowledge in class. The main purpose of the online and offline blended teaching mode is to create learning situations around the theme of learning, guide and inspire learning, and enable students to continuously improve their application and innovation capabilities through teamwork in the process of practical results show, problem analysis and resolution, etc. After-class practice is also an indispensable part of deepening students' knowledge. Students apply what they have learned in practice. In this way students' practical 
ability, expression ability, problem analysis and resolution ability, teamwork ability, etc.will be fully trained and improved.

\subsection{Practical Application of Online and Offline Blended Teaching}

In the process of online and offline blended teaching of the course, we follow the principle of offline focus and online difficulty-breaking.

In the regular offline classroom teaching, we teach the basic and key knowledge points, however, But for obscure knowledge points, such as the operation to insert and delete data in a singly linked list, we can use multimedia to help students understand. Although in the classroom we can also use multimedia presentations, but classroom teaching time is limited, Less presentations will cause some students to fail to understand, More presentations will delay the overall teaching progress. At this time, we can make the difficulty for video forms, and then upload them to the online course platform. Students who do not understand can use online resources to learn at any time.

Because the differences between individual students and the understanding of knowledge are different,so we advocate layered guidance. The contents of the offline classroom teaching should be suitable for all students, ensuring that the difficulty is moderate, which is often not enough for students with excellent learning ability. How can we meet the needs of these students to gain more knowledge? We can arrange some more difficult tasks on the online platform, and do not require all students to do them, let the students who have more ability to complete them. This can effectively improve the ability of individual students under the premise of ensuring the balanced development of students.

\subsection{Application Effects of Bitc Online Platform}

In practice, we build the course on Bitc online platform to realize the online teaching. Bitc online platform can realize the entire process of education and teaching management, as well as support for big data applications and decision analysis. Through this platform, we can combine students' learning process data to mine the correlation between the data to provide reference and support for daily teaching behavior intervention and decision-making. The platform can also realize multi-dimensional teaching quality analysis, achieve multi-index, multi-level, multi-dimensional evaluation of students and teachers. Using this platform, teachers can also flexibly publish various questionnaires and follow-up surveys. The effective use of the platform can provide information support for the main links in the teaching work, and realize the standardized and scientific teaching management,as shown in Figure 2.

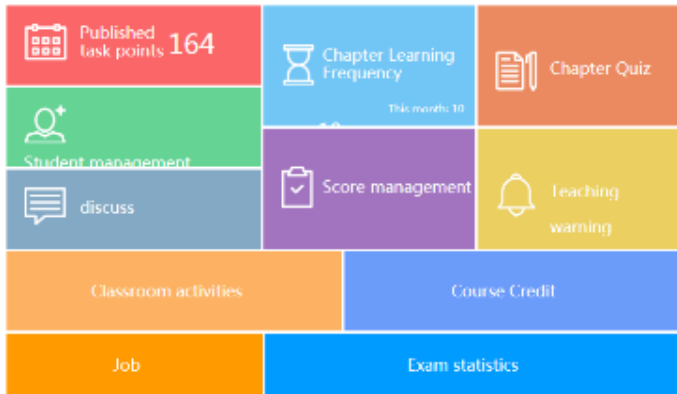

Figure 2 Global statistics view

\subsection{Analysis of Online and Offline Blended Teaching Mode}

The biggest advantage of online teaching is that as long as there is network and equipment, teaching and learning can be carried out at any time. The uploaded video, PPT and other teaching resources can be repeatedly studied after class, which benefits the students who are good at autonomous learning.However, the shortcomings of online teaching is that teachers can not more intuitively test students, because teachers and students do not meet, so in terms of testing students' learning effects,it will have some disadvantages. Online and offline blended teaching is an effective carrier for the deep integration of information technology and education teaching,and it can integrate the advantages of offline learning with the personalization of online learning.So it is the development trend of teaching reform.

\section{CONCLUSIONS}

With the rapid development of the Internet, information technology, and artificial intelligence, online and offline blended teaching mode will inevitably become new teaching forms.

In the future, we will continue to explore the research on the combination of online and offline blended teaching mode and innovative teaching applications, based on the network teaching environment, big data and artificial intelligence support, and holographic digital education teaching resources support. Thereby, the exploration of optimizing the traditional educational teaching mode with the application of digital teaching resources is realized, building an innovative demonstration of a new mode of digital resources application and establishing a new mode of open sharing of digital resources. Using diverse digital education resources, We will do our best to explore the blended precision teaching mode of the whole process, multi-element online and offline organic connection and realize the integration of digital resources before, in and after class. 


\section{ACKNOWLEDGMENT}

This work is supported by Beijing Educational Informatization Project-research on the new teaching mode based on digital educational resources.

\section{REFERENCES}

[1] Oche, Emaikwu Sunday. Assessing the relative effectiveness of three teaching methods in the measurement of students' achievement in Mathematics [J]. Journal of Emerging Trends in Educational Research and Policy Studies. 2012(4).

[2] Deborah Sellnow-Richmond,Michael G. Strawser,Deanna D. Sellnow.Student perceptions of teaching effectiveness and learning achievement: A comparative examination of online and hybrid course delivery format $[\mathrm{J}]$. Communication Teacher. 2020(3).

[3] Model for teaching effectiveness index for decisions [J]. Bijan Mashaw. Int. J. of Teaching and Case Studies. 2009(2).

[4] Madeline Cloonan, Abbey L. Fingeret Developing teaching materials for learners in surgery [J] Surgery, 2020, 167(4).

[5] Roger H. Kim, John D. Mellinger Educational strategies to foster bedside teaching [J] Surgery, 2020, 167(3). 